\title{
BMJ Open Demographic and clinical characteristics of hospitalised unintentional poisoning in Aboriginal and non-Aboriginal preschool children in New South Wales, Australia: a population data linkage study
}

\author{
Caroline Lee, ${ }^{1}$ Mark Hanly, ${ }^{1}$ Natasha Larter, ${ }^{2}$ Karen Zwi, ${ }^{2}$ Susan Woolfenden, ${ }^{2}$ \\ Louisa Jorm ${ }^{1}$
}

To cite: Lee C, Hanly M, Larter $\mathrm{N}$, et al. Demographic and clinical characteristics of hospitalised unintentional poisoning in Aboriginal and non-Aboriginal preschool children in New South Wales, Australia: a population data linkage study. BMJ Open 2019;9:e022633. doi:10.1136/ bmjopen-2018-022633

- Prepublication history and additional material for this paper are available online. To view these files, please visit the journal online (http://dx.doi. org/10.1136/bmjopen-2018022633).

Received 2 March 2018 Revised 23 November 2018 Accepted 13 December 2018

Check for updates

(c) Author(s) (or their employer(s)) 2019. Re-use permitted under CC BY-NC. No commercial re-use. See rights and permissions. Published by BMJ.

${ }^{1}$ Centre for Big Data Research in Health, University of New South Wales, Sydney, New South Wales, Australia

${ }^{2}$ Department of Community Child Health, Sydney Children's Hospitals Network, Sydney, New South Wales, Australia

Correspondence to

Caroline Lee;

caroline.lee@unsw.edu.au

\section{ABSTRACT}

Objectives To investigate differences in demographic and clinical characteristics of Aboriginal and non-Aboriginal children aged 0-4 years hospitalised for unintentional poisoning in New South Wales (NSW), Australia.

Design and setting Retrospective whole-of-population cohort analysis of linked hospital and mortality data for 2000-2014.

Participants All children (Aboriginal and non-Aboriginal) under the age of 5 years who were born in a hospital in NSW from 2000 to 2009.

Outcomes The primary outcome was hospitalisation for unintentional poisoning. Logistic regression was used to estimate odds of poisoning hospitalisation for Aboriginal and non-Aboriginal children. Poisoning agents and clinical outcomes were compared by Aboriginality.

Results The cohort included 767119 children, including 28528 (3.7\%) Aboriginal children. Aboriginal children had approximately three times higher rates of hospitalised poisoning (1.34\%) compared with non-Aboriginal children $(0.41 \%)$. Poisoning incidence peaked at $2-3$ years of age. Male sex, socioeconomic disadvantage and geographical remoteness were associated with higher odds of poisoning hospitalisation for Aboriginal and non-Aboriginal children, but associations with disadvantage and remoteness were statistically significant only for non-Aboriginal children. Most (83\%) poisonings were caused by pharmaceutical agents. Few Aboriginal and non-Aboriginal children had repeat admissions for poisoning; most had a length of stay of 1 day or less. Only $8 \%$ of poisoning admissions involved contact with a social worker.

Conclusion Commonly used medications in the general population contribute to poisonings among both Aboriginal and non-Aboriginal preschool-aged children. This study highlights a need to develop culturally safe poisoning prevention strategies and policies.

\section{INTRODUCTION}

Poisoning is a leading cause of childhood injury worldwide. ${ }^{1}$ Preschool children (0-4

\section{Strengths and limitations of this study}

- This study's strengths include its focus on preschool-aged children, large sample size due to the whole-of-population design, and minimal recall bias due to the use of routinely collected administrative data.

- However, the use of administrative data limited the available covariates, so risk factors such as parent demographics, supervision and storage practice, and clinical information such as symptoms and treatment details could not be examined.

- Children were identified as Aboriginal if they had been recorded at least once as Aboriginal ('ever-identified' algorithm), which enhances the proportion of Aboriginal children recorded using hospital data but may introduce bias in that sicker children with more frequent hospitalisations have more opportunities for identification.

- Our analysis of poisoning agents was limited to the International Classification of Diseases 10th edition taxonomy, and in some circumstances it was not possible to determine specific agents, for example, 'other' categories.

years) have a higher risk of poisoning-related hospital admissions ${ }^{2-4}$ due to their developmental stage ${ }^{5}$ and are a priority for prevention. Among preschool children, poisoning incidence peaks at 2 to 3 years of age, ${ }^{3}{ }^{5-8}$ reflecting their increased mobility and exploratory skills. ${ }^{569}$

Pharmaceutical substances, such as overthe-counter and prescription medications, cause most unintentional poisonings in Australia. ${ }^{4}$ Among preschool children in Australia, the most common causes of hospitalised pharmaceutical poisoning include 
analgesic, antiepileptic, psychotropic, and other systemic and cardiovascular medications. ${ }^{34710-12}$

Various demographic and socioeconomic risk factors contribute to poisoning among preschool children. Factors relating to the child (male, higher birth order), parents (younger age, perinatal depression, alcohol misuse), unsafe storage and socioeconomic deprivation are associated with increased poisoning risk. ${ }^{1-3} 7813-16$ In Australia, remote areas also have higher poisoning rates. ${ }^{416}$

Poisoning represents one of the largest Indigenous child health inequalities in high-income countries, with rate ratios for hospitalisation and mortality ranging from 1.1 to 3.9 and 1.2 to 15.4 , respectively. ${ }^{17} \mathrm{~A}$ recent whole-of-population study in New South Wales, Australia reported that Aboriginal children had nearly three times higher risk of poisoning hospitalisation compared with non-Aboriginal children. ${ }^{18}$ Existing studies about poisoning among Indigenous children in high-income countries have limitations, such as the lack of a non-Indigenous comparison group and wide age ranges up to 18 years old that do not differentiate younger children. ${ }^{19}{ }^{20}$ Previous Australian studies of poisoning among preschool children in the general population have not focused on Aboriginal children. ${ }^{35721}$ The current literature about poisoning among Aboriginal children in Australia is limited in its examination of risk factors and clinical outcomes. ${ }^{11} 121822$ Specific poisoning agents and clinical outcomes of poisoning for Aboriginal children have not been described. ${ }^{2101623}$

This is the first study to examine the characteristics of unintentional poisoning among preschool-aged Aboriginal Australian children. The study aimed to answer questions that will inform prevention efforts for this at-risk group during a time of peak incidence:

1. Are the demographic risk factors for poisoning (sex, socioeconomic status and geographical remoteness) similar for both Aboriginal and non-Aboriginal children?

2. Which agents most frequently result in poisoning hospitalisation and are they different for Aboriginal and non-Aboriginal children?

3. Are the clinical outcomes from hospitalised poisoning similar for Aboriginal and non-Aboriginal children?

\section{METHODS}

\section{Study design and setting}

This was a retrospective, whole-of-population cohort study using linked hospital and mortality data for New South Wales (NSW), Australia for the period 2000 to 2014. In 2011, NSW had a population of 7218529 people, of whom an estimated 208476 (2.9\%) were Aboriginal or Torres Strait Islander. ${ }^{24}$

\section{Data sources}

This study was part of the Indigenous Health Outcomes Patient Evaluation project which compares health outcomes for Aboriginal and non-Aboriginal people in

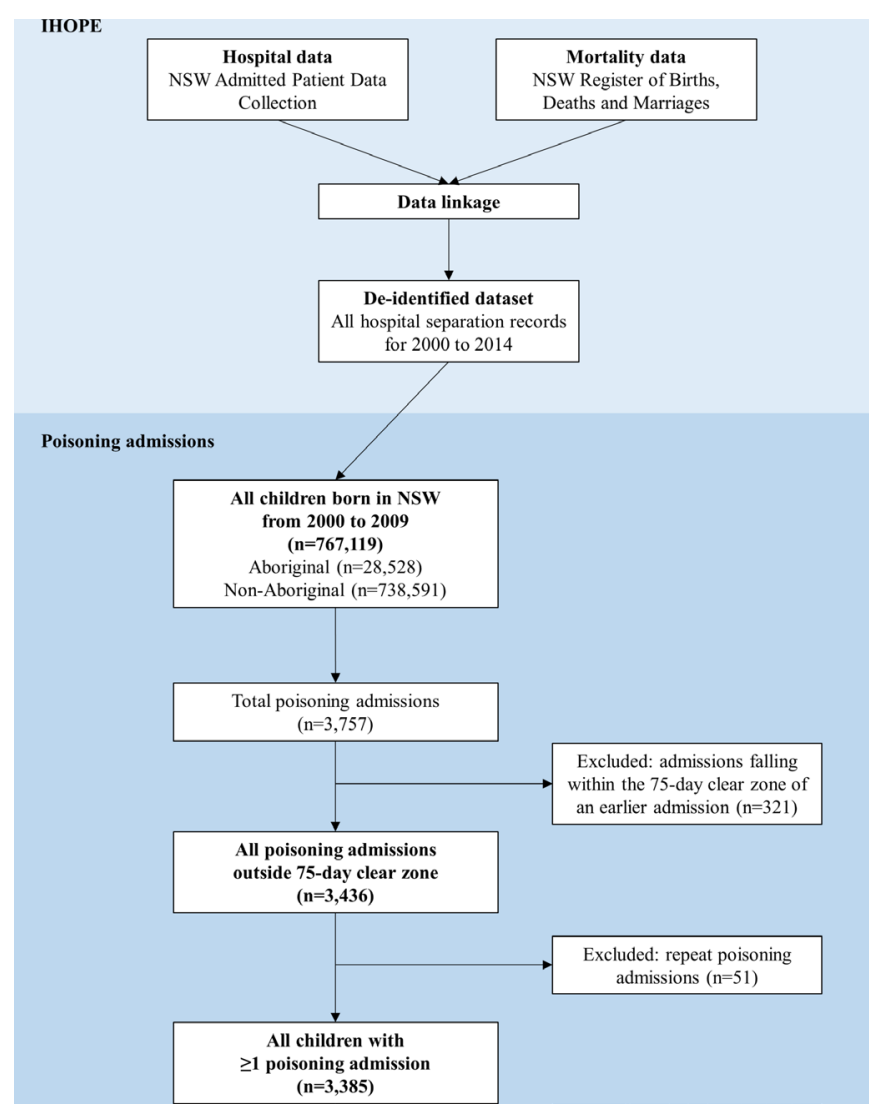

Figure 1 Indigenous Health Outcomes Patient Evaluation (IHOPE) data sources and study cohort selection. NSW, New South Wales.

NSW using linked hospital and mortality data (figure 1). Hospital data were sourced from the Admitted Patient Data Collection (APDC) and mortality data from the NSW Register of Births, Deaths and Marriages (RBDM). Probabilistic data linkage was performed by the NSW Centre for Health Record Linkage (http://www.cherel. org.au). De-identified, linked datasets were supplied to the researchers.

The RBDM contains details for all deaths in NSW. The APDC contains records for all inpatient separations (discharges, transfers and deaths) for all public and private hospitals and day procedure centres in NSW. Each separation record contains information about patient demographics, diagnoses and procedures. Diagnoses are coded according to the International Classification of Diseases and Related Problems Australian Modification, 10th revision (ICD-10-AM). Separations are hereafter referred to as hospital admissions.

\section{Participants}

Children born in a NSW hospital between 1 June 2000 and 31 March 2009 were followed from birth until their fifth birthday. Birth records were identified from the APDC dataset using the criteria of 'live born infant' (ICD-10-AM code Z38) in any diagnosis field. This birth cohort has been previously described. ${ }^{18}$ 


\section{Aboriginal status}

Aboriginal status is routinely recorded in the APDC. The main analyses used an 'ever-identified' algorithm that coded children as Aboriginal if they were ever identified as Aboriginal, yielding higher proportions of Aboriginal children compared with the most recent record or birth record (online supplement 1 ). ${ }^{25}$ To test the sensitivity of this identification method, all analyses were repeated using Aboriginality defined by the most recent record or birth record.

\section{Study variables}

The main outcome was hospitalisation for unintentional poisoning, defined as an acute accidental exposure to, or overdose of, a toxic substance, whether accessed by a child or incorrectly administered by another person (wrong dosage, agent or frequency). The study focused on ingested poisoning agents likely to require similar prevention approaches, including pharmaceutical (over-the-counter and prescription) and non-pharmaceutical agents, and excluding environmental exposures (online supplement 2). Poisoning cases were identified by a primary diagnosis of injury with an ICD-10-AM code T36-65, excluding toxic effect of metals (T56), carbon monoxide and other gases (T58-59) and noxious substances, venoms and food substances (T61-64).

A poisoning admission was defined from the start date of an episode of care to the date of separation or death. Multiple hospital admissions within a short time could be due to follow-up visits, transfer between hospitals or change in care type within a hospital, related to the same poisoning event. Records falling within 75 days after the initial poisoning admission were excluded, based on the published 'clear zone' for poisoning. ${ }^{26}$

Available demographic variables included child's age, sex and area-level variables for socioeconomic disadvantage (Australian Bureau of Statistics Socioeconomic Indices for Areas Index of Relative Socioeconomic Advantage and Disadvantage (IRSAD) ${ }^{27}$ ) and remoteness (Accessibility/Remoteness Index of Australia (ARIA) ${ }^{28}$ ) based on the child's statistical local area of residence at birth. Due to small numbers in some categories, IRSAD was divided into tertiles, and ARIA into four categories 'Major Cities', 'Inner Regional', 'Outer Regional' and 'Remote/Very Remote' as used previously. ${ }^{18}$ The age of first poisoning hospitalisation was analysed by single-year intervals for Aboriginal and non-Aboriginal children.

Poisoning agents were included if they were recorded in any diagnosis field (up to 50 fields). Clinical outcomes (repeat admissions, length of stay (LOS), procedures) were analysed for all poisoning admissions. LOS included the total number of hospital days related to the initial admission, and any subsequent admissions within 75 days. Procedures were classified at the 'block' level according to the Australian Classification for Health Interventions, eighth edition. ${ }^{29}$

\section{Statistical analysis}

Differences in poisoning incidence were compared by demographic characteristics using $\chi^{2}$ tests, stratified by Aboriginality (RQ1). The crude and adjusted odds of poisoning hospitalisation associated with demographic characteristics were estimated using logistic regression (RQ1). Separate models were built for Aboriginal and non-Aboriginal children. Fully adjusted models included the variables sex, socioeconomic disadvantage and remoteness.

Among children with a poisoning hospitalisation, incidence was examined by year of age (RQ1). The groups of poisoning agents and the 10 most common individual agents were examined across all poisoning admissions (RQ2). Differences in poisoning agents (both groups and individual agents) by Aboriginality were tested using $\chi^{2}$ tests (RQ2). The number and types of procedures and LOS were examined for all poisoning admissions, and compared by Aboriginality, with descriptive statistics and $\chi^{2}$ tests (RQ3). Data were prepared with SAS V.9.4 (SAS Institute) and analysed in Stata V.14 (StataCorp).

\section{Patient and public involvement}

Patients were not directly involved in the development of the research question, outcome measures or study design. All patient data were de-identified prior to analysis. Results were presented at a public Aboriginal community health forum in La Perouse, Sydney, Australia, attended by health providers and community members. Results were also presented at an international injury prevention conference attended by policy-makers and researchers, and to the Board of Kidsafe Australia. A patient information poster will be developed and presented to Kidsafe Board.

\section{RESULTS \\ Study population}

The cohort included 767119 children born in NSW between 1 July 2000 and 31 March 2009, of whom 28528 $(3.7 \%$ ) were Aboriginal (figure 1). From 2000 to 2014, there were 3757 hospital admissions with a primary diagnosis of poisoning. Of these, 321 fell within the 75-day clear zone and were not analysed as new admissions. This left 3436 poisoning admissions for 3385 individual children, including 382 (11\%) Aboriginal children. Aboriginal children were significantly over-represented among children who had been poisoned $\left(\chi^{2}=543.6, \mathrm{p}<0.001\right)$.

\section{Demographic characteristics}

Poisoning admission by demographic characteristics for all children in the cohort are shown in table 1. More Aboriginal than non-Aboriginal children lived in the most disadvantaged areas and in Remote or Very Remote areas. The proportion of children hospitalised for poisoning was higher for boys compared with girls, and increased with increasing socioeconomic disadvantage and increasing 


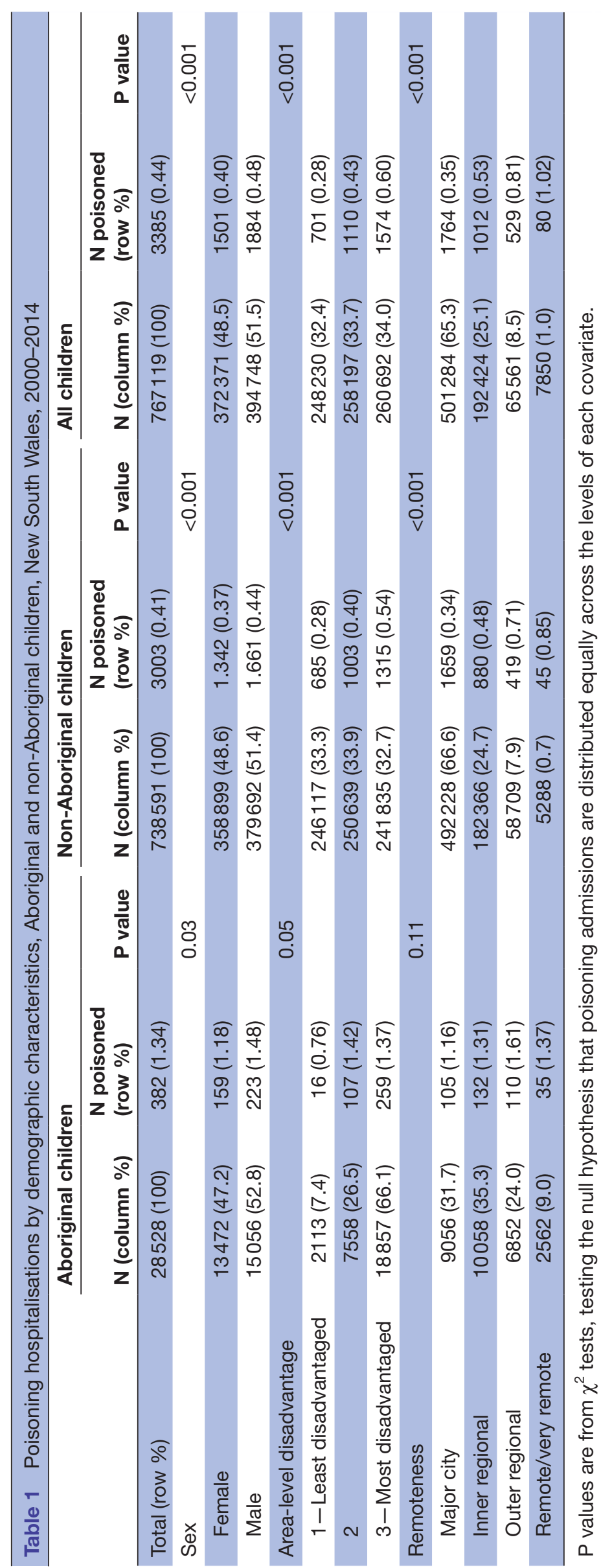




\begin{tabular}{|c|c|c|c|c|c|}
\hline \multirow[t]{2}{*}{ Variables } & \multicolumn{2}{|c|}{ Aboriginal $(n=28,528)$} & \multicolumn{2}{|c|}{ Non Aboriginal $(n=738,591)$} & \multirow{2}{*}{$\begin{array}{l}\text { - Aboriginal } \\
\text { - non-Aboriginal }\end{array}$} \\
\hline & OR $(95 \% \mathrm{Cl})$ & aOR $(95 \% \mathrm{Cl})$ & OR $(95 \% \mathrm{Cl})$ & aOR $(95 \% \mathrm{Cl})$ & \\
\hline \multicolumn{6}{|l|}{ Sex } \\
\hline Female & 1 & 1 & 1 & 1 & \\
\hline Male & $1.26(1.03-1.54)$ & $1.27(1.03-1.56)$ & $1.17(1.09-1.26)$ & $1.17(1.09-1.26)$ & $\circ$ \\
\hline \multicolumn{6}{|c|}{ Area-level disadvantage } \\
\hline 1 (Least disadvantaged) & 1 & 1 & 1 & 1 & \\
\hline 2 & $1.88(1.11-3.19)$ & $1.84(1.07-3.15)$ & $1.44(1.31-1.59)$ & $1.34(1.21-1.48)$ & $\rightarrow$ \\
\hline 3 (Most disadvantaged) & $1.83(1.10-3.03)$ & $1.57(0.92-2.69)$ & $1.96(1.79-2.15)$ & $1.64(1.48-1.81)$ & $\because$ \\
\hline \multicolumn{6}{|l|}{ Remoteness } \\
\hline Major Cities & 1 & 1 & 1 & 1 & \\
\hline Inner Regional & $1.13(0.88-1.47)$ & $1.06(0.82-1.39)$ & $1.43(1.32-1.56)$ & $1.33(1.22-1.44)$ & $\bullet$ \\
\hline Outer Regional & $1.39(1.06-1.82)$ & $1.39(1.02-1.88)$ & $2.13(1.91-2.37)$ & $1.66(1.47-1.87)$ & 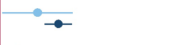 \\
\hline Remote/Very Remote & $1.18(0.80-1.74)$ & $1.18(0.78-1.79)$ & $2.54(1.89-3.42)$ & $1.97(1.46-2.66)$ & - \\
\hline & & & & & $1 \begin{array}{r}2 \\
\text { Ddds Ratio }\end{array}$ \\
\hline
\end{tabular}

Figure 2 Crude and adjusted ORs with 95\% Cls for poisoning hospitalisation, by demographic factors, Aboriginal and nonAboriginal children, New South Wales, 2000-2014. aOR, adjusted OR. Fully adjusted models included variables sex, area-level disadvantage and geographical remoteness.

remoteness for both Aboriginal and non-Aboriginal children.

Crude and adjusted odds for poisoning hospitalisation for Aboriginal and non-Aboriginal children are shown in figure 2. Male sex was significantly associated with increased risk of poisoning for both Aboriginal (adjusted OR (aOR) 1.27, 95\% CI 1.03 to 1.56) and non-Aboriginal children (aOR 1.17, 95\% CI 1.09 to 1.26). For non-Aboriginal children, poisoning risk increased with increasing socioeconomic disadvantage and increasing geographical remoteness. For Aboriginal children, increasing socioeconomic disadvantage was also associated with higher poisoning risk, although CIs were wider. However, geographical remoteness was not significantly associated with an increasing poisoning risk.

Incidence by 1-year age intervals was similar among Aboriginal and non-Aboriginal children (table 2). Poisoning admissions increased from 1 year, were most frequent between 2 and 3 years, and were least frequent at under 1 year and over 4 years of age.

Table 2 Age at poisoning admission, Aboriginal and nonAboriginal children, New South Wales, 2000-2014

\begin{tabular}{lcc}
\hline & \multicolumn{2}{c}{$\begin{array}{c}\text { Non-Aboriginal } \\
\text { children } \\
\text { Age (years) }\end{array}$} \\
$\mathbf{N}$ (column \%) & (column \%) \\
\hline$<1$ & $21(6)$ & $220(7)$ \\
$1-2$ & $96(25)$ & $952(32)$ \\
$2-3$ & $152(40)$ & $1211(40)$ \\
$3-4$ & $73(19)$ & $446(15)$ \\
$4-5$ & $40(10)$ & $174(6)$ \\
Total & 382 & 3003 \\
\hline
\end{tabular}

\section{Poisoning agents}

Pharmaceutical agents caused most poisonings for both Aboriginal $(83 \%)$ and non-Aboriginal $(81 \%)$ children (table 3).

The most frequent groups of poisoning agents were similar for both Aboriginal and non-Aboriginal children: non-opioid analgesic, antipyretic and antirheumatics (including paracetamol and ibuprofen); antiepileptic, sedative-hypnotic and antiparkinsonism medications; psychotropics; and cardiovascular medications (table 3). Aboriginal children had a higher proportion of poisoning admissions from cardiovascular medications than non-Aboriginal children ( $14 \%$ and $11 \%, \mathrm{p}=0.032)$, while non-Aboriginal children had a higher proportion from non-opioid analgesic, antipyretic and antirheumatics $(15 \%$ and $8 \%, \mathrm{p}<0.001)$ and autonomic nervous system medications $(8 \%$ and $5 \%, \mathrm{p}=0.048)$.

The two most frequent individual poisoning agents were benzodiazepines $(11 \%)$ and 4-aminophenol derivatives (paracetamol) (11\%) (table 3). Together with other antihypertensives not elsewhere classified, they accounted for one in three poisoning admissions. Benzodiazepines and other antihypertensives not elsewhere classified were the two most common individual agents for Aboriginal children and caused a higher proportion of admissions for Aboriginal than non-Aboriginal children (benzodiazepines: $14 \%$ and $10 \%, \mathrm{p}=0.025$; other antihypertensives not elsewhere classified: $10 \%$ and $6 \%$, $\mathrm{p}=0.002$ ).

\section{Clinical outcomes}

Aboriginal and non-Aboriginal children had similar clinical outcomes in terms of repeat admissions, LOS and procedures (table 4). There was one death from poisoning during the study period. 
Table 3 Poisoning agents by class and 10 most frequent individual agents, for Aboriginal and Non-Aboriginal children, New South Wales, 2000-2014

\begin{tabular}{|c|c|c|c|c|}
\hline \multirow[b]{2}{*}{ ICD-10 diagnosis code } & \multirow{2}{*}{$\begin{array}{l}\text { Total } \\
\text { N (\%) }\end{array}$} & \multirow{2}{*}{$\frac{\text { Aboriginal }}{\mathrm{N}(\%)}$} & \multirow{2}{*}{$\begin{array}{l}\text { Non-Aboriginal } \\
\mathrm{N}(\%)\end{array}$} & \multirow[b]{2}{*}{ P value } \\
\hline & & & & \\
\hline T36-65: All poisoning admissions & $3436(100)$ & $391(11)$ & $3045(89)$ & \\
\hline T36-50: Pharmaceutical ${ }^{\star}$ & $2859(83)$ & $318(81)$ & $2541(83)$ & 0.291 \\
\hline T51-65: Non-pharmaceutical* & $588(17)$ & $76(19)$ & $512(17)$ & 0.195 \\
\hline \multicolumn{5}{|l|}{ Pharmaceutical agents } \\
\hline T36-37: Antibiotics, anti-infectives, antiparasitics $†$ & $47(1)$ & $7(2)$ & $40(1)$ & 0.445 \\
\hline T38: Hormones and synthetic substitutes & $141(4)$ & $22(6)$ & $119(4)$ & 0.107 \\
\hline T38.3: Insulin and oral hypoglycaemic drugs & $96(3)$ & $17(4)$ & $79(3)$ & 0.048 \\
\hline T39: Non-opioid analgesics, antipyretics and antirheumatics & $493(14)$ & $31(8)$ & $462(15)$ & $<0.001$ \\
\hline T39.1: 4-Aminophenol derivatives & $374(11)$ & $24(6)$ & $350(11)$ & 0.001 \\
\hline T40: Narcotics and hallucinogens & $178(5)$ & $25(6)$ & $153(5)$ & 0.25 \\
\hline T41: Poisoning by anaesthetics and therapeutic gases & $14(0)$ & $0(0)$ & $14(0)$ & 0.179 \\
\hline T42: Antiepileptic, sedative-hypnotic and antiparkinsonism & $492(14)$ & $66(17)$ & $426(14)$ & 0.125 \\
\hline T42.4: Benzodiazepines & $370(11)$ & $55(14)$ & $315(10)$ & 0.025 \\
\hline T43: Psychotropic drugs, not elsewhere classified & $394(11)$ & $55(14)$ & $339(11)$ & 0.087 \\
\hline T43.2: Other and unspecified antidepressants & $149(4)$ & $15(4)$ & $134(4)$ & 0.606 \\
\hline T44: Autonomic nervous system drugs & $251(7)$ & $19(5)$ & $232(8)$ & 0.048 \\
\hline $\begin{array}{l}\text { T44.3: Other parasympatholytics and spasmolytics, not } \\
\text { elsewhere classified }\end{array}$ & $93(3)$ & $7(2)$ & $86(3)$ & 0.236 \\
\hline T44.7: Beta adrenoreceptor antagonists, not elsewhere classified & $105(3)$ & $7(2)$ & $98(3)$ & 0.122 \\
\hline T45: Systemic and haematological agents & $286(8)$ & $23(6)$ & $263(9)$ & 0.063 \\
\hline T45.0: Antiallergic and antiemetic drugs & $150(4)$ & $14(4)$ & $136(4)$ & 0.42 \\
\hline T45.4: Iron and its compounds & $83(2)$ & $\ddagger$ & $\ddagger$ & \\
\hline T46: Cardiovascular system drugs & $382(11)$ & $56(14)$ & $326(11)$ & 0.032 \\
\hline T46.5: Other antihypertensives, not elsewhere classified & $211(6)$ & $38(10)$ & $173(6)$ & 0.002 \\
\hline T47: Gastrointestinal system drugs & $80(2)$ & $8(2)$ & $72(2)$ & 0.694 \\
\hline T48: Smooth and skeletal muscle and respiratory system agents & $98(3)$ & $6(2)$ & $92(3)$ & 0.096 \\
\hline $\begin{array}{l}\text { T49: Topical agents and opthalmological, otorhinolaryngological } \\
\text { and dental drugs }\end{array}$ & $143(4)$ & $12(3)$ & $131(4)$ & 0.25 \\
\hline $\begin{array}{l}\text { T50: Diuretics and other and unspecified drugs, medicaments and } \\
\text { biological substances }\end{array}$ & $207(6)$ & $22(6)$ & $185(6)$ & 0.725 \\
\hline $\begin{array}{l}\text { T50.9: Other and unspecified drugs, medicaments and } \\
\text { biologicals }\end{array}$ & $94(3)$ & $10(3)$ & $84(3)$ & 0.819 \\
\hline \multicolumn{5}{|l|}{ Non-pharmaceutical agents } \\
\hline T51: Toxic effect of alcohol & $35(1)$ & $5(1)$ & $30(1)$ & 0.586 \\
\hline T52: Toxic effect of organic solvents & $185(5)$ & $22(6)$ & $163(5)$ & 0.822 \\
\hline $\begin{array}{l}\text { T53: Toxic effect of halogen derivatives of aliphatic and aromatic } \\
\text { hydrocarbons }\end{array}$ & $10(0)$ & $0(0)$ & $10(0)$ & 0.256 \\
\hline $\begin{array}{l}\text { T54-55: Toxic effect of corrosive substances, soaps and } \\
\text { detergents }^{\dagger}\end{array}$ & $132(4)$ & $17(4)$ & $115(4)$ & 0.58 \\
\hline T57: Toxic effect of other inorganic substances & $0(0)$ & $0(0)$ & $0(0)$ & \\
\hline T60: Toxic effect of pesticides & $106(3)$ & $12(3)$ & $94(3)$ & 0.985 \\
\hline T65: Toxic effect of other and unspecified substances & $124(4)$ & $21(5)$ & $103(3)$ & 0.047 \\
\hline
\end{tabular}

*May exceed total number of poisoning admissions due to multiple agents per admission.

†Categories combined due to small cell numbers.

$\ddagger$ Suppressed due to small cell numbers. 
Table 4 Clinical outcomes of Aboriginal and non-Aboriginal children with a poisoning hospitalisation, New South Wales, 2000-2014

\begin{tabular}{lccc}
\hline & Aboriginal N (\%) & Non-Aboriginal N (\%) & Total N (\%) \\
\hline Total no of poisoning admissions & $391(100)$ & $3045(100)$ & $3436(100)$ \\
\hline Repeat admissions & $9(2)$ & $42(1)$ & $51(1)$ \\
\hline Length of stay (days) & & & \\
\hline$<1$ & $125(32)$ & $1085(36)$ & $1210(35)$ \\
\hline 1 & $225(58)$ & $1707(56)$ & $1932(56)$ \\
\hline 2 & $25(6)$ & $158(5)$ & $183(5)$ \\
\hline $3+$ & $16(4)$ & $95(3)$ & $111(3)$ \\
\hline Total no of procedures & $39(10)$ & $335(11)$ & $374(11)$ \\
\hline Allied health interventions & $27(7)$ & $233(8)$ & $260(8)$ \\
\hline Airway and ventilation & $5(1)$ & $32(1)$ & $37(1)$ \\
\hline Other (including diagnostics and pharmacotherapy) ${ }^{*}$ & $7(2)$ & $70(2)$ & $77(2)$ \\
\hline
\end{tabular}

${ }^{*}$ Combined due to small cell numbers.

\section{Repeat admissions}

There were 51 repeat admissions (1\% of poisoning admissions). Of these, 42 were non-Aboriginal and 9 were Aboriginal. Due to small numbers, no further analysis of this group was undertaken.

\section{Length of stay}

Most children (91\%) hospitalised for poisoning had a short LOS of $\leq 1$ day. Excluding one outlier, LOS ranged from $<1$ to 18 days. The distribution of LOS was similar for Aboriginal and non-Aboriginal children (table 4, $\chi^{2}=3.4147, \mathrm{p}=0.332$ ).

\section{Procedures}

Most children hospitalised for poisoning had no recorded procedures $(89 \%, 3062 / 3436)$, and this proportion was similar for Aboriginal and non-Aboriginal children. Of the 374 hospital admissions with a recorded procedure, the majority were allied health interventions, mostly a social worker consultation ( $8 \%$ of poisoning admissions).

\section{Sensitivity analyses}

Compared with the ever-identified method, defining Aboriginal status by most recent record and birth record reduced the numbers of children in the cohort to 25891 and 21576, respectively, and the number of children poisoned to 319 and 246, respectively (online supplement 1 table 1). Other findings remained similar (online supplement 1 tables 2-5). For example, the magnitude of the association between poisoning admission and sex, area-level disadvantage and remoteness were similar with overlapping CIs. The profile of age at admission, common poisoning agents and clinical outcomes were also consistent across all three identification methods.

\section{DISCUSSION}

Compared with non-Aboriginal children, preschool Aboriginal children in NSW have about three times the rate of hospitalised poisoning, but similar patterns of poisoning risk across available demographic factors, poisoning agents and clinical outcomes.

Among both Aboriginal and non-Aboriginal children, the incidence of hospitalised poisoning increased from age 1 , peaked at 2 to 3 years and declined by 4 years, consistent with previous studies. ${ }^{35-811}$ Male sex was a significant risk factor for both Aboriginal and non-Aboriginal children, consistent with findings from the general population $^{2} 3716$ and among Aboriginal children in NSW. ${ }^{11}$ Higher poisoning rates among boys may be due to earlier development of motor skills than risk perception. ${ }^{5}$

Poisoning risk increased with socioeconomic disadvantage among Aboriginal and non-Aboriginal children, and increased with geographical remoteness among non-Aboriginal children. Socioeconomic disadvantage is a well-established risk factor for unintentional injury, ${ }^{140}$ and children from low-income backgrounds have a higher poisoning risk ${ }^{131431}$ due to more comorbidities and medication usage, less access to childcare and storage equipment, and overcrowding. ${ }^{31}$

Geographical remoteness was associated with significantly increased poisoning risk among non-Aboriginal children. In contrast, no significant trend between poisoning and geographical remoteness was evident among Aboriginal children, possibly reflecting small subgroup sizes and wider CIs. This may also reflect additional barriers in access to health services, or differences in housing, medication availability or other social factors experienced by Aboriginal people in remote areas.

Broadly, higher poisoning hospitalisations in remote areas may suggest more children are being poisoned, but also that children presenting to rural hospitals are more likely to be admitted ${ }^{416}$ for reasons including distance from facilities, limited specialist services and delayed diagnostic tests. ${ }^{23}{ }^{32}$ Differences in poisoning agents by geographical region may also contribute. Some have suggested children in rural areas are more likely to be 
poisoned by chemicals such as pesticides. However, evidence is conflicting, with this hypothesis supported by a Queensland study ${ }^{2}$ but not a subsequent NSW study which did not find higher rates of chemical poisoning in rural areas. ${ }^{10}$

Several reasons may contribute to the disparity in hospitalised poisoning between Aboriginal and non-Aboriginal children. Aboriginal people experience a higher burden of socioeconomic disadvantage and chronic disease, potentially exposing children to more medications. Overcrowding and poor housing disproportionally affects Aboriginal people and contributes to stress, poor supervision and health problems. ${ }^{33}$ Higher levels of mobility among Aboriginal people ${ }^{33}$ may expose children to medications belonging to different people in their own or other people's homes.

Pharmaceuticals, including adult and paediatric overthe-counter and prescription medications, are the leading causes of hospitalised unintentional poisonings among both Aboriginal and non-Aboriginal children. The most frequent groups of poisoning agents identified in this study-analgesic; psychotropic, antiepileptic and sedative; and cardiovascular agents-are commonly prescribed medications in Australia. Of these, the most frequent individual agents benzodiazepines, 4-aminophenol derivatives (paracetamol) and other antihypertensives not elsewhere classified (for example clonidine) accounted for almost one-third of all poisoning admissions.

Chronic diseases are highly prevalent, affecting 11 million Australians. In 2014-2015, 117 million medications were prescribed by a general practitioner, a $17 \%$ increase since 2010-2011. ${ }^{34}$ This rising medication use in Australia could be contributing towards unintentional childhood poisonings, as has been demonstrated in the USA, where pharmaceutical poisonings in children have been associated with trends in adult medication prescriptions. ${ }^{35}$

Benzodiazepines were the most common poisoning agent for Aboriginal children, similar to a previous report among Aboriginal and non-Aboriginal people in NSW. ${ }^{22}$ Benzodiazepines are widely prescribed in Australia, often for anxiety and insomnia. Aboriginal people experience a higher burden of mental health issues ${ }^{36}$ and higher rates of benzodiazepine poisoning among Aboriginal children may reflect higher adult usage, although we cannot confirm this using the available data.

Antihypertensives not elsewhere classified were the second most frequent poisoning agent for Aboriginal children in our study. In Australia, this largely includes clonidine, which is used for child behavioural disorders. ${ }^{37}$ Aboriginal children, particularly those from disadvantaged backgrounds, have a higher risk of emotional or behavioural difficulties. ${ }^{38}{ }^{39}$ Childhood clonidine poisoning has been found in other research to be often caused by a child accidentally ingesting clonidine belonging to another child such as an older sibling. ${ }^{40}$

Most children hospitalised for poisoning had a short LOS of $\leq 1$ day and few required procedures, consistent with previous reports. ${ }^{3} 2332$ Allied health interventions were the most common procedure, yet fewer than 1 in 10 poisoning hospitalisations had a recorded social worker consultation. Social workers can support parents during a stressful hospitalisation and provide injury prevention education when they are more likely to be receptive. ${ }^{41}$ Low use of this resource presents a lost opportunity for safety promotion. However, cultural sensitivity is required to promote safety and not instigate blame or fear, given the intergenerational trauma around child removal for Aboriginal families. ${ }^{42}$

\section{Strengths and limitations}

This study's strengths include its focus on preschoolaged children, whole-of-population design and minimal recall bias using routinely collected administrative data. However, covariates were limited, and risk factors previously demonstrated to affect poisoning risk were unavailable, such as perinatal depression, ${ }^{13} 14$ younger maternal age, ${ }^{8}$ parental alcohol misuse, ${ }^{8} 13$ poor storage and supervision, ${ }^{21}$ household dwelling and socioeconomic deprivation. ${ }^{13}{ }^{14}$ Clinical information (such as time to presentation, symptoms, laboratory results, treatment, complications $^{7}$ ) were also unavailable. The use of an area-level index for socioeconomic status may introduce ecological bias. For example, individuals from low socioeconomic households who live in relatively advantaged areas will be misclassified.

The under-identification of Aboriginal children in Australian public hospital data can affect estimates of health outcomes. ${ }^{25}$ This study used an 'ever-identified' algorithm for children recorded at least once as Aboriginal in order to maximise the number of poisoning events in Aboriginal children for analysis. Although this method may introduce bias in comparison of event rates between Aboriginal and non-Aboriginal people due to differential increase in identification among sicker individuals with more hospital records, such comparisons were not the main purpose of our study. Also, results of the sensitivity analysis indicated that the methods of identification did not alter the main conclusions (online supplement 1 ).

Hospital admissions represent only a fraction of poisonings. Our study does not reflect the complete spectrum of early childhood poisoning incidents, but captures the most severe hospitalised cases with the largest impact on children and health services.

Finally, our analysis of poisoning agents was limited to the ICD-10 taxonomy. In some circumstances, it was not possible to determine specific agents, for example, 'other' categories.

\section{Implications for practice and prevention}

Reducing the poisoning rate among Aboriginal children requires combined strategies of household storage interventions, accessible poisons information centres and enforcement of packaging legislation. ${ }^{43}$ No known injury prevention programmes have specifically addressed unintentional poisoning in Aboriginal communities ${ }^{44}$; 
however, safe storage of medications is known to be key to childhood poisoning prevention. ${ }^{15}$ Aboriginal families and low-income families may face barriers in promoting safe storage due to costs of safety equipment and prohibitions on home installations in public housing or rental properties. ${ }^{45} 46$ Providing low-cost or free equipment can improve household storage practices, particularly with education and fitting assistance. ${ }^{47}$ The 'Safe Homes Safe Kids' programme provided home safety education and devices to Aboriginal families in the Illawarra region of NSW. ${ }^{47}$ Future research involving community consultation is needed to address poisoning prevention in Aboriginal communities, considering factors such as poverty, trauma, housing and family separation. ${ }^{48}$

\section{CONCLUSION}

Unintentional poisoning is most prevalent among preschool-aged children and disproportionately affects Aboriginal children. This study confirmed the inequity in hospitalised poisonings between Aboriginal and non-Aboriginal children, and demonstrated that adult and child medications commonly used in the general population contribute to poisonings among both groups. With a rising prevalence of chronic disease and increases in prescription medication use among both Aboriginal people and the wider community, keeping children safe from unintentional poisoning should be a priority. Further research and policy development is needed to investigate culturally safe prevention strategies that include improved packaging, safe storage and education.

Acknowledgements The authors wish to thank Dr Holger Moller who prepared the dataset prior to the study period; this study builds upon knowledge generated by his previous research. The authors also wish to thank Professor Nicholas Buckley, Dr Jane Bell, Dr Ruth Barker and Professor Sallie Pearson for their assistance in the interpretation of poisoning agents; and Professor Rebecca Ivers, Professor Kathleen Clapham and Dr Kathleen Falster for consultation about translating the research findings for policy and practice.

Contributors CL, SW, LJ and MH contributed to the conception and design of the study, including the research questions and the analysis. CL wrote each drafts and, together with $\mathrm{MH}$, produced the tables and figures. LJ, SW and MH provided technical support and supervision throughout the study. All authors contributed to the drafting of the work, approval of the final manuscript and critical interpretation of its findings, with particular contributions from KZ, SW and NL regarding the translation of findings with other stakeholders for prevention.

Funding This work was supported by the Australian National Health and Medical Research Council (573113).

Competing interests None declared.

Patient consent for publication Not required.

Ethics approval Ethics approval was granted by the New South Wales Population and Health Services Research Committee (2009/04/141) and the Aboriginal Health and Medical Research Council Committee (684/09).

Provenance and peer review Not commissioned; externally peer reviewed.

Data sharing statement No additional data are available.

Open access This is an open access article distributed in accordance with the Creative Commons Attribution Non Commercial (CC BY-NC 4.0) license, which permits others to distribute, remix, adapt, build upon this work non-commercially, and license their derivative works on different terms, provided the original work is properly cited, appropriate credit is given, any changes made indicated, and the use is non-commercial. See: http://creativecommons.org/licenses/by-nc/4.0/.

\section{REFERENCES}

1. World Health Organization. World report on child injury prevention. Switzerland: World Health Organization, 2008. 9241563575.

2. Reith DM, Pitt WR, Hockey R. Childhood poisoning in Queensland: an analysis of presentation and admission rates. $J$ Paediatr Child Health 2001;37:446-50.

3. Cripps R, Steel D. Childhood poisoning in Australia. South Australia: AlHW National Injury Surveillance Unit, Flinders University, 2006.

4. Tovell A, McKenna K, Bradley C, et al. Hospital separations due to injury and poisoning, Australia 2009-10. Canberra: Australian Institute of Health and Welfare, 2012. Cat. no. INJCAT 145.

5. Schmertmann M, Williamson A, Black D. Stable age pattern supports role of development in unintentional childhood poisoning. Inj Prev 2008;14:30-3.

6. Agran PF, Anderson C, Winn D, et al. Rates of pediatric injuries by 3-month intervals for children 0 to 3 years of age. Pediatrics 2003;111(6 Pt 1):e683-e692.

7. Hoy JL, Day LM, Tibballs J, et al. Unintentional poisoning hospitalisations among young children in Victoria. Inj Prev 1999;5:31-5

8. Tyrrell EG, Orton E, Tata LJ, et al. Children at risk of medicinal and non-medicinal poisoning: a population-based case-control study in general practice. Br J Gen Pract 2012;62:e827-e833.

9. Rodgers GB, Franklin RL, Midgett JD. Unintentional paediatric ingestion poisonings and the role of imitative behaviour. Inj Prev 2012;18:103-8.

10. Lam LT. Childhood and adolescence poisoning in NSW, Australia: an analysis of age, sex, geographic, and poison types. Inj Prev 2003;9:338-42.

11. Möller H, Falster K, Ivers R, et al. Closing the Aboriginal child injury gap: targets for injury prevention. Aust $N Z J$ Public Health 2017:41:8-14.

12. Pointer S. Australian Institute of Health and Welfare (AlHW). Hospitalised injuries in Aboriginal and Torres Strait Islander children and young people 2011-13. Canberra: AlHW, 2016. Cat no. INJCAT 172.

13. Orton E, Kendrick D, West $\mathrm{J}$, et al. Independent risk factors for injury in pre-school children: three population-based nested case-control studies using routine primary care data. PLOS One 2012; 7:e35193.

14. Laursen B, Nielsen JW. Influence of sociodemographic factors on the risk of unintentional childhood home injuries. Eur $J$ Public Health 2008;18:366-70.

15. Kendrick D, Majsak-Newman G, Benford P, et al. Poison prevention practices and medically attended poisoning in young children: multicentre case-control study. Inj Prev 2017;23:93-101.

16. O'Connor PJ. Differentials in poisoning rates of young Australian children according to residential location and geographical remoteness. Inj Prev 2005;11:204-6.

17. Möller $\mathrm{H}$, Falster $\mathrm{K}$, Ivers $\mathrm{R}$, et al. Inequalities in unintentional injuries between indigenous and non-indigenous children: a systematic review. Inj Prev 2015;21(e1):e144-e152.

18. Möller H, Falster K, Ivers $\mathrm{R}$, et al. Inequalities in hospitalized unintentional injury between Aboriginal and non-Aboriginal children in New South Wales, Australia. Am J Public Health 2016;106:899-905.

19. Alaghehbandan R, Sikdar KC, MacDonald D, et al. Unintentional injuries among children and adolescents in Aboriginal and nonAboriginal communities, Newfoundland and Labrador, Canada. Int $J$ Circumpolar Health 2010;69:61-71.

20. Johnson SJ, Sullivan M, Grossman DC. Injury hospitalizations among American Indian youth in Washington. Inj Prev 1999;5:119-23.

21. Schmertmann M, Williamson A, Black D, et al. Risk factors for unintentional poisoning in children aged 1-3 years in NSW Australia: a case-control study. BMC Pediatr 2013;13:88.

22. Walter S. Mortality and hospitalisation due to injury in the Aboriginal population of New South Wales. North Sydney, Australia: New South Wales Department of Health, 2010.

23. Cheng DR, Ip CC, Cck I. Unintentional paediatric poisoning in rural Victoria: incidence and admission rates. Aust $J$ Rural Health 2012;20:339-43.

24. Australian Bureau of Statistics. Estimates of Aboriginal and Torres Strait Islander Australians. http://www.abs.gov.au/ausstats/abs@.nsf/ $\mathrm{mf} / 3238.0 .55 .001$

25. Gialamas A, Pilkington R, Berry J, et al. Identification of Aboriginal children using linked administrative data: consequences for measuring inequalities. J Paediatr Child Health 2016;52:534-40.

26. Lestina DC, Miller TR, Smith GS. Creating injury episodes using medical claims data. J Trauma 1998;45:565-9.

27. Australian Bureau of Statistics. Socio-economic indexes for areas. 2013 http://www.abs.gov.au/websitedbs/censushome.nsf/home/ seifas. 
28. Australian Bureau of Statistics. The Australian Statistical Geography Standard (ASGS) remoteness structure. http://www.abs.gov.au/ websitedbs/D3310114.nsf/home/remoteness+structure.

29. Australian Institute of Health and Welfare. Australian Classification of Health Interventions (ACHI) 8th edition. http://meteor.aihw.gov.au/ content/index.phtml/itemld/514008.

30. Birken CS, Macarthur C. Socioeconomic status and injury risk in children. Paediatr Child Health 2004;9:323-5.

31. Groom L, Kendrick D, Coupland C, et al. Inequalities in hospital admission rates for unintentional poisoning in young children. Inj Prev 2006;12:166-70.

32. Sherrard J, Sweidan M, Robinson J, et al. Barriers to child poisoning prevention: why does child resistant packaging fail? Melbourne: Monash University Accident Research Centre, 2005.

33. Bailie RS, Wayte KJ. Housing and health in Indigenous communities: key issues for housing and health improvement in remote Aboriginal and Torres Strait Islander communities. Aust J Rural Health 2006;14:178-83.

34. Australian Institute of Health and Welfare (AIHW). Australia's health 2016. Canberra: AlHW, 2016. Australia's health series no. 15. Cat no. AUS 199.

35. Burghardt LC, Ayers JW, Brownstein JS, et al. Adult prescription drug use and pediatric medication exposures and poisonings. Pediatrics 2013;132:18-27.

36. Jorm AF, Bourchier SJ, Cvetkovski S, et al. Mental health of Indigenous Australians: a review of findings from community surveys. Med J Aust 2012;196:118-21.

37. Australian Medicines Handbook Pty Ltd. Australian Medicines Handbook Adelaide, 2017. https://amhonline.amh.net.au/.

38. Zubrick S, Lawrence D, Silburn S, et al. The Western Australian Aboriginal child health survey: the health of Aboriginal children and young people: Telethon Institute for Child Health Research, 2004
39. Shepherd CC, Li J, Mitrou F, et al. Socioeconomic disparities in the mental health of indigenous children in Western Australia. BMC Public Health 2012;12:756.

40. Sinha Y, Cranswick NE. Clonidine poisoning in children: a recent experience. J Paediatr Child Health 2004;40:678-80.

41. Zonfrillo MR, Melzer-Lange M, Gittelman MA. A comprehensive approach to pediatric injury prevention in the emergency department. Pediatr Emerg Care 2014;30:56-62.

42. Bennett B, Zubrzycki J, Bacon V. What do we know? The experiences of social workers working alongside Aboriginal people. Australian Social Work 2011;64:20-37.

43. Adams S, Elkington J, MacKay JM KZ, et al. Child Safety Good Practice Guide: good investments in unintentional child injury prevention and safety promotion. Sydney: Sydney Children's Hospitals Network, 2016.

44. Senserrick T, Hinchcliff R, Ivers R, et al. Aboriginal injury prevention projects: a rapid review. Ultimo, Australia: Sax Institute for NSW Health and the George Institute, 2010.

45. Smithson J, Garside R, Pearson M. Barriers to, and facilitators of, the prevention of unintentional injury in children in the home: a systematic review and synthesis of qualitative research. Inj Prev 2011;17:119-26.

46. Gibbs L, Waters E, Sherrard J, et al. Understanding parental motivators and barriers to uptake of child poison safety strategies: a qualitative study. Inj Prev 2005;11:373-7.

47. Achana FA, Sutton AJ, Kendrick D, et al. The effectiveness of different interventions to promote poison prevention behaviours in households with children: a network meta-analysis. PLoS One 2015;10:e0121122.

48. Ivers R, Clapham K, Senserrick T, et al. Injury prevention in Australian indigenous communities. Injury 2008;39:S61-S67. 